\title{
Educación, maestro y ciudadanía en el Bolívar Grande (Colombia), 1870-1889: variables de una continuidad ${ }^{1}$
}

\author{
Education, Teachers and Citizenship \\ in Bolívar Grande (Colombia), \\ 1870-1889: Variables of a Continuity
}

\author{
Luisinho Eder Salas Martínez \\ Universidad Autónoma de Zacatecas \\ luisinhoeder@hotmail.com
}

\begin{abstract}
Resumen
A partir del análisis de las fuentes oficiales e instruccionistas que circularon en el Bolívar Grande, en este trabajo se hace una reflexión en torno a la continuidad histórica entre el liberalismo radical y la Regeneración en Colombia. Se consideran tres elementos centrales: la preocupación por la educación pública, el papel de las escuelas de primeras letras, las normales en la formación de ciudadanos modernos y, por último, la representación del maestro de escuela como modelo de ciudadano "ideal". Estas líneas se inscriben en la tendencia contemporánea de los estudios en América Latina sobre educación, ciudadanía y nación; en particular, sobre las distintas herramientas que utilizan los nacientes estados para la alineación del ciudadano y en las que la escuela, a partir del maestro, desempeña un papel esencial.
\end{abstract}

Palabras clave: educación, maestro, ciudadanía, escuelas, Colombia

\section{Abstract}

Based on the analysis of official and instructional sources that circulated in the Bolivar Grande, this article reflects on the historical continuity between the periods of radical liberalism and Regeneration in Colombia. Three elements are taken into account: the concern for public education, the role of the

\footnotetext{
${ }^{1}$ Este artículo es producto de mi tesis de maestría, Educación, maestro y ciudadanía. De la transición del liberalismo radical a la Regeneración: el caso del Bolívar Grande, 1870-1899, desarrollada en la Universidad Autónoma de Zacatecas Francisco García Salinas bajo la dirección del Dr. René Amaro Peñaflores. La investigación contó con el apoyo de una beca del Conacyt.
} 
elementary and normal schools in the formation of modern citizens, and the representation of the school teacher as the model of the "ideal" citizen. This work is part of current trends in Latin American studies on education, citizenship and nation. In particular, it is part of those trends that examine the different tools used by the emerging states for citizen formation at school, where teachers played an essential role.

Keywords: education, teacher, citizenship, schools, Colombia.

\section{Introducción}

En los últimos años, los temas de educación, ciudadanía, formación del Estado-nación, el lugar que ocupa la escuela en la iniciación ciudadana y el papel del maestro de primeras letras en el mismo sentido, han cobrado un lugar notable en el seno de la historiografía en distintos espacios geográficos de América Latina y Europa. Estos estudios hacen énfasis en la preocupación de las élites políticas, liberales y conservadoras, respecto al campo educativo y su importancia como vehículo privilegiado de socialización en la construcción de los nuevos estados decimonónicos. Asimismo, develan la centralidad de la escuela pública a través del maestro para construir un individuo en estrecha correspondencia con las demandas políticas y sociales que requería el mundo republicano que se aspiraba conquistar y edificar (Roldán, 2012: 39-69; Meníndez, 2012: 191-203; Ríos, 2005: 302; Amaro, 2016; Traffano, 2012: 71-95; Lionetti, 2005: 1225-1255; Serrano, 2003: 550-564; Bazant, 1993: 173-189; Acevedo, 2011: 73-100; Agulhon, 1989; Rosanvallon, 1999: 449).

En el caso de Colombia la historiografía sobre educación no es ajena a pensar estas variables. Los estudios existentes exploran este campo como un elemento central para lograr encauzar al país por las sendas del progreso y la civilización tan en boga en el imaginario de las élites republicanas durante el siglo xix. Respecto a esta tendencia, fue durante este periodo cuando se dio una lucha constante por popularizar el ideal de ciudadano pero, sobre todo, por separar o integrar la influencia de la Iglesia católica en la enseñanza (Loaiza, 2011: 469; Alarcón, 2002: 256; González, 2005: 262; Palacios, 2002: 261-278; Salas, 2009: 107; Andrade, 2011: 154-172; Báez, 2004: 447; Cardona, 2001; Jaramillo, 1982: 230-250; Rausch, 1993: 128; Silva, 1991: 61-63).

Ahora bien, el aporte de este artículo, si bien no es novedoso en los debates que sobre el tema se han materializado en otras realidades geográficas, sí es muy importante desde el campo de la historia regional en Colombia, no sólo porque atiende la naturaleza diversa, fragmentada y polarizada que caracteriza al territorio colombiano durante la centuria decimonónica y en gran parte del siglo Xx, sino también por las particularidades propias del 
Bolívar Grande en la época objeto de estudio. En efecto, su población, su organización social, política y cultural, y sus características geográficas - pues no en vano contaba para la fecha con dos de las principales ciudades puertos de Colombia: Cartagena y Barranquilla, sin restarle importancia a otros espacios geográficos como Magangué y Mompox, por sólo mencionar algunos - son elementos que distinguen históricamente a este territorio de cualquier otro a nivel nacional.

No menos importante es la persistencia de varios vacíos historiográficos e interrogantes aún por resolver respecto a dos de los periodos centrales de la historia política del país durante las tres últimas décadas del siglo XIX: el liberalismo radical² y la Regeneración ${ }^{3}$. Durante estos periodos se hicieron múltiples esfuerzos por formar el nuevo Estado-nación colombiano moderno y la educación pública jugó un papel relevante, hecho que es más notable para el territorio del Bolívar Grande. ${ }^{4}$ Sobre este último, pese a los aportes ya mencionados de nivel nacional, no existen estudios sistemáticos que den cuenta del papel de la escuela pública en la formación del ciudadano moderno, y mucho menos han abordado la figura del maestro de escuela como modelo de ciudadano "ideal" y su importancia en las tres últimas décadas del siglo XIX en el campo de la educación oficialista. Por tanto, pretendemos res-

\footnotetext{
2 Para el contexto objeto de estudio, en Colombia se conoce como liberalismo radical a un grupo de políticos pertenecientes a un ala del partido liberal que, con la puesta en marcha de la Constitución de 1863, buscaba la aplicación en el país de los más puros principios del liberalismo clásico. Este texto constitucional pasaría a la historia de este territorio por ser el más liberal de todos las que se hubieran organizado. Lo consignado en la Constitución fue la culminación del más amplio y ambicioso proyecto político del siglo XIX, que inició en 1845 bajo la primera presidencia de Tomas Cipriano de Mosquera y se consolidó con las Ilamadas Reformas de medio siglo para finalizar con la llegada al poder de los políticos conservadores bajo la tutela de la Constitución de 1886, que tenía como objetivo la organización de una sociedad moderna a partir del desarrollo de la democracia y de la ciudadanía política. Conceptos como opinión pública, esfera pública, ciudadanía, liberalismo político y económico, sufragio universal, libertad, igualdad, etc., se volvieron de uso cotidiano y debían ser los elementos estructurantes de la sociedad que se aspiraba conquistar. Se buscaba, por un lado, la consolidación de un gobierno de y para las mayorías, encarnado en el régimen democrático, en el que los ciudadanos participaran activamente y donde el Estado fuera una institución pública. Un sugestivo trabajo que analiza este tema es "El uso privado de la autoridad pública en el Estado Soberano de Bolívar, 1863-1878" de Roicer Flórez (2010).

${ }^{3}$ Para el contexto objeto de estudio, en Colombia se conoce como Regeneración a un grupo de políticos de corte conservador, liderado por el cartagenero Rafael Núñez, que impone a partir de la Constitución política de 1886, entre muchas otras cosas, una visión centralizada de las funciones del Estado y una estrecha relación entre éste y la Iglesia católica. Este texto constitucional intenta restablecer los principios de autoridad, orden y soberanía del país, ya que aumenta el periodo presidencial de dos a seis años, reimplanta la pena de muerte, fiscaliza a la prensa escrita y reconoce a la religión católica como la religión oficial del país; igualmente, ordena la conformación de una sola y única armada al servicio de un poder ejecutivo, también único, y reglamenta la educación pública religiosa cristiana no obligatoria (Margot, 2011)

${ }^{4}$ Para la época objeto de estudio, Bolívar Grande se entiende como los actuales departamentos de la Región Caribe Colombiana (Atlántico, Sucre, Córdoba, Bolívar), exceptuando el Magdalena. Durante la Colonia y hasta finales del decenio de 1850 se le conoció como la provincia de Cartagena. Bajo el régimen federal se le llamó Estado Soberano de Bolívar y, a partir de 1886, se le conoció como Departamento de Bolívar. Entre 1905, 1954 y 1966 quedó reducido al actual departamento de ese nombre, pues sufrió el desprendimiento de las tres primeras unidades político-administrativas mencionadas (véase Solano, Florez y Malkún, 2008: 63-122).
} 
ponder a interrogantes como ¿cuáles fueron las principales características del proyecto educativo tanto del liberalismo radical como de la Regeneración en el Bolívar Grande?, ¿cuál es la función que cumplen las escuelas de primeras letras y las escuelas normales que surgieron en la época en la formación del maestro-ciudadano?, ¿de qué manera se construyó la imagen del maestro de escuela como el modelo de ciudadano "ideal" que luego se aplicó en los educandos? La hipótesis que guía este artículo es contraria a una historiografía de corte nacional, regional y local (Jaramillo, 1982: 230-250; Silva, 1991: 61-63; González Stephan, 1979; Rubiano, 2002: 421-452; Berquist, 1977; Palacios, 2002: 261-278; Verbel, 2005; Pacheco y Castellanos, 2010; Molina, 1999: 102; Viviel, 2002: 50-75) que privilegia en sus análisis una ruptura y marcadas diferencias entre los modelos políticos, liberales y el de la Regeneración, en las tres últimas décadas del siglo XIX, hasta el punto de plantear que el ascenso de la Regeneración entrañó el desmantelamiento del sistema educativo nacional iniciado por los liberales respecto a la preocupación por la educación pública, la funcionalidad de los espacios escolares como escenarios en la formación de ciudadanos y en la representación que hacen del maestrociudadano. Nosotros sostenemos, con base en estas tres variables, que hubo una continuidad en estos proyectos políticos aparentemente disímiles de concebir el Estado. En otras palabras, la educación es, por una parte, la herramienta esencial en la formación del Estado-nación en Colombia y en el Bolívar Grande y las escuelas son el lugar privilegiado en la alineación del ciudadano moderno, pero además el maestro fue pieza clave en la popularización de la enseñanza y como formador de los ciudadanos que necesitaba la república, así como un verdadero modelo de vida en sociedad y la imagen paradigmática en la ciudadanía; la persona a quien niños, adultos y la sociedad en general debían mirar como ejemplo a seguir en su desenvolvimiento dentro del nuevo escenario republicano.

Este artículo se inscribe dentro de la tendencia historiográfica en América Latina que pretende analizar el tema de la formación del Estado-nación y de la ciudadanía desde múltiples variables - entre ellas la educación pública - de las cuales el fenómeno de la disputa entre centralismo y federalismo es una de las que ha tenido mayor importancia en los últimos años. Asimismo, se pretende contribuir modestamente a la historiografía centrada en el estudio de la educación y el desarrollo de la ciudadanía en el Caribe y en el contexto nacional; en particular, de las distintas herramientas utilizadas por los nacientes estados para la construcción del ciudadano para lo cual la escuela, a partir del maestro, desempeñó un papel esencial durante el periodo objeto de estudio.

Para dar respuesta a lo anterior el trabajo se estructura en tres partes. La primera es un breve esbozo de las principales características del proyecto educativo desarrollado por los liberales y los regeneradores, y su preocupación por la educación pública como un elemento central en el proceso de formación del Estado-nación en Colombia y en el Bolívar Grande. La segunda da cuenta del papel que cumplen tanto la escuela primaria como la escuela 
normal como epicentros privilegiados en el proceso de formación de ciudadanos modernos. La tercera y última parte analiza la importancia que le otorgan los gobiernos, en el tránsito del liberalismo radical a la Regeneración, al maestro formado en la Escuela Normal de Bolívar como modelo de ciudadano "ideal" en el contexto objeto de estudio.

\section{Breve panorama de la educación durante el periodo liberal radical y regenerador}

El 8 de mayo de 1863 representantes de los gobiernos de Antioquia, Bolívar, Boyacá, Cauca, Cundinamarca, Magdalena, Santander, Tolima y Panamá firmaron la Constitución de Rionegro que daría paso a la conformación de los Estados Unidos de Colombia. Esta carta constitucional es considerada la más anticlerical en la historia de Colombia. Invocaba el nombre y la autoridad del pueblo en vez del nombre de Dios, legislador del universo. De igual forma, dinamizó la absoluta separación entre la Iglesia y el Estado (Rausch, 1993: 150). Esta constitución recopiló en forma coherente la ideología liberal, consagró las libertades individuales, el derecho a la igualdad, la libertad de dar o recibir instrucción, la libertad de profesar cualquier religión con tal de que no fuera incompatible con la soberanía nacional ni perturbara la paz, entre otros elementos.

Bajo este emblema los liberales radicales iniciaron una serie de reformas económicas, políticas y sociales. La reforma en el campo económico tuvo que ver con la instauración del libre comercio como doctrina económica que vincularía al país al mercado mundial. En el campo político se estableció un orden federal que permitió total autonomía a los estados de la unión, y en lo social los radicales propusieron una clara división de poderes entre la Iglesia y el Estado. Se dinamizó la desamortización de bienes de manos muertas y la exclusión de las comunidades religiosas como estrategias para superponer el poder político sobre el religioso. Se trataba de transformar un país "casi colonial, conservador, intolerante y católico en una Nación republicana, secular, tolerante, ilustrada y moderna" (Mesa, 2016: 221). Para estos políticos había llegado la hora de encauzar el territorio colombiano por las sendas del progreso y la civilización lo cual se debía traducir, precisamente, en fomentar la instrucción pública para todos y todas; en modernizar el Estado en términos económicos, políticos, sociales, culturales y, obviamente, en la ampliación de la ciudadanía política. En esos propósitos de modernización la educación se constituyó en pieza fundamental para los gobiernos radicales. Al decir de Jaime Jaramillo "la fe en la educación como la vía más apropiada para conquistar la civilización que entonces se perseguía tan afanosamente, quizás no se tuvo nunca ni se ha vuelto a tener en la historia nacional como en aquel momento" (Jaramillo, 
1982: 264). Los liberales estaban convencidos de que si instruían a las masas "éstas aceptarían y defenderían las instituciones e ideas liberales y a la vez garantizarían el progreso económico del país" (Alarcón, Conde y Santos, 2002: 15). Esta es la razón de sus esfuerzos en crear un sistema de educación pública y por llevar la escuela de primeras letras a todos los rincones de la república.

La instrucción pública, según la élite política liberal, era el único camino para cultivar los valores de aquel que refundaría la Nación, el ciudadano, y además un elemento con el que se pretendía fortalecer la idea de cohesión nacional. ${ }^{5}$ Pero también -y aquí sigo los planteamientos que para el caso de Chile decimonónico plantea Sol Serrano- se buscaba con esta política de escolarización "romper los lazos comunitarios de tipo tradicional y forjar unos nuevos basados en la racionalidad de la cultura escrita; construir una sociedad de individuos que se comportasen racionalmente en el espacio privado identificado con la familia y el trabajo y en el espacio público, identificado con la ciudadanía y la manutención del orden social" (Serrano, 1998: 341). Es decir, se intentaba dejar atrás prácticas inherentes a la tradición y el rezago social y cultural que adornaba la sociedad colombiana, pero sobre todo impregnar a los nuevos ciudadanos de herramientas modernas como leer y escribir para su desenvolvimiento en la nueva colectividad de tipo republicana que se intentaba construir. En la misma prensa regional de la época se reproduce ese interés de instruir a la población y educar para el progreso de la república. En uno de esos medios periodísticos se insiste en alejarse de las pugnas entre los partidos y en no armar debates religiosos, que nada bueno le hacen al país. En donde se debe prestar atención, según la prensa, es en la necesidad de:

[...] alejar de la niñez de tanta preocupación absurda i evitar que en su alma se albergue tanto odio, tanta intolerancia, tanto frenesí de exterminio. La condición jeneral de nuestro pueblo es la de las tinieblas; por eso es que todavía hallan eco en su corazón las mentidas promesas de bienestar, i los engañosos consejos del fanatismo. Eduquemos, eduquemos. Querer marchar a oscuras es tropezar i caer por consiguiente. No puede haber progreso sin luz. Solo la educación bien entendida produce ese justo medio, que dista tanto del fanatismo como de la demagogia. No comprendemos como exijir virtudes sin formar caracteres. Así, pues, para levantar al país de esta postración en que se encuentra, hai que adoptar estos dos medios: la educación i el trabajo. Con el primero viene la ilustración; con el segundo viene la riqueza. Teniendo paz i orden, planteando escuelas i construyendo vías de comunicación, haciendo cada

\footnotetext{
${ }^{5}$ Biblioteca Nacional de Colombia (en adelante, BNC), La Escuela Normal, Bogotá, 18 de febrero de 1871. Concebir la educación como un elemento de cohesión nacional durante este periodo no es un acto exclusivo de Colombia. En Chile y México también ocurre lo mismo. Unos sugestivos ensayos donde se puede analizar esta tendencia son: "La ciudadanía examinada: el control estatal de la educación en Chile (1810-1870)" de Sol Serrano (2003: 551-564); y "Estado nacional y escuelas rurales en el espacio andino y pampino del norte de Chile (Tarapacá 1880-1930)" de Luis Castro (2011: 139-173)
} 
cual su deber i obrando todos en beneficio de la patria común, podemos asegurar que el porvenir será nuestro. ${ }^{6}$

El discurso es muy dicente pues no sólo se apropia de las dificultades que limitan el progreso, sino que además coloca a la educación y el trabajo como los vehículos para transitar hacia la conquista de ese tópico. Construir escuelas y educar para la producción son las claves para pensar en un mejor mañana e ir creando, paso a paso, las bases para una cultura escrita y laboral. En la medida en que el niño se instruya en esos principios, seguramente irán desapareciendo valores de intolerancia que tanto daño le hacen al país y particularmente al Bolívar Grande por las continuas guerras civiles; y, contrario a ello, se fortalecerán los dispositivos ideológicos que se intentan reproducir y establecer. Existió la necesidad de educar a las masas para dotarlas de sus derechos políticos. La oportunidad era histórica y el ambiente de progreso que se manejaba durante la centuria decimonónica, no sólo en Colombia sino en el resto de países de América Latina, era el punto del alzhéimer al que se pretendía llegar. Sin duda, la educación pública sería uno de los puentes para lograr ese fin. Asumen tal tópico como el vehículo que coadyuva al proceso de formación del Estado-nación, así como también la ampliación de la ciudadanía y los tan anhelados progreso y civilización, tan en boga durante el siglo XIX, en los distintos espacios geográficos latinoamericanos. Al alfabetizar al mayor número de personas se transitaba de una "soberanía popular" a una "soberanía racional"; es decir, "a un sufragio capacitario, que tenía como fin hacer coincidir al pueblo teórico de la soberanía con el pueblo real de la política. La educación sería el medio para la formación gradual del pueblo soberano" (Serrano, 1998: 348).

La Constitución de 1863 -liderada por los liberales radicales - se inclinaba por una forma de gobierno federalista, laica y anticlerical que consagraba principios de libertades individuales, esenciales para la concepción de la ciudadanía; derechos a la igualdad, libertad de instrucción gratuita y obligatoria, por mencionar sólo algunos aspectos relacionados con el iusnaturalismo. Contrario a ello, la carta magna de 1886 establece el proyecto político de la Regeneración y desde su primer epígrafe enuncia: "[...] en nombre de Dios fuente suprema de toda autoridad", por lo que la preeminencia del elemento religioso y cristiano será un factor primordial; de hecho, considera la religión católica, apostólica y romana la única religión oficial del país y promulga que sea respetada y protegida como elemento esencial del orden social; promueve la reconstitución de la forma de república unitaria y centralizada, dividida en departamentos y no en estados soberanos; la educación pública, organizada y dirigida por la Religión Católica, gratuita pero no obligatoria; establece, asimismo, que los sacerdotes puedan ser nombrados empleados para instrucción pública o de beneficencia; libertad de

\footnotetext{
${ }^{6}$ BNC, La Verdad, 25 de diciembre de 1877, Cartagena.
} 
prensa, pero sujeta a las leyes estatales; restricciones en la libertad de poseer y comprar armas, es decir que sólo el gobierno lo podrá hacer; la ciudadanía se adquirirá al ser mayor de 21 años y ejercer alguna profesión, arte u oficio, o al tener ocupación lícita u otro medio legítimo y conocido de subsistencia; si no se es ciudadano tampoco se pueden ejercer funciones electorales ni desempeñar empleos públicos, fortalecimiento del poder ejecutivo, entre otros as-

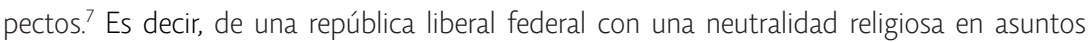
educativos y políticos que intentó construir una colectividad de valores modernos se pasó a un régimen que se inclinaba por el rescate de esos valores tradicionales y donde la puesta en marcha de una política moderna pasaría, sin duda, por la tutelar importancia y el filtro del fuero eclesiástico. De un intento por deshacer el tejido social durante la época liberal, se volvió a pensar la sociedad con la intención de anular al individuo y mantener el orden de esa estructura social. Por tanto, a lo que asistimos en nuestro país entre 1886 y 1899, en términos de principios jurídicos, es a una "refundación" de la patria en procesos políticos, sociales, económicos y culturales; a la preservación del orden, a una estrecha relación entre la Iglesia y el Estado y un apego casi obsesivo a la religión y sus principios cristianos que debían determinar y guiar al hombre en sociedad y al nuevo ciudadano que requería la república, envestido de virtudes católicas.

Tal como ocurrió durante la época liberal, la instrucción pública es un elemento esencial para los gobiernos de la Regeneración y un instrumento fundamental para el progreso del país, así como una preocupación constante para su proyecto educativo y político. Pero con la diferencia de que durante todo este periodo, contrario a sus antecesores, la instrucción pública primaria será gratuita mas no obligatoria. Se dividen las escuelas en elementales y superiores, se preceptúa para que la religión católica sea enseñada de manera obligatoria en las universidades, en los colegios, en las escuelas y en los demás centros de enseñanza, en tanto que los padres no se opongan abiertamente a ellos, y se les confiere a los señores curas la facultad de dar la enseñanza cristiana en los establecimientos públicos que lo exijan, y que ellos lo determinen. Esto, de hecho, es constitucional pues en el artículo 41 de la Constitución de 1886 se establece que "la educación pública será organizada y dirigida en concordancia con la religión católica. La instrucción primaria costeada con fondos públicos

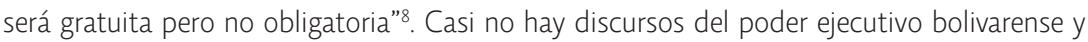

${ }^{7}$ Constitución Política de Colombia, disponible en: <http://biblio.juridicas.unam.mx/libros/5/2212/13.pdf>, (fecha de consulta: 23/02/2016); una mirada profunda en torno a las discusiones de los puntos señalados en las sesiones del Consejo Nacional Constituyente que terminaron materializadas en este texto pueden verse en BNC, Registro de Bolivar, durante los meses de enero, febrero mayo, agosto y septiembre de 1886.

${ }^{8}$ Constitución Política de Colombia, disponible en: <http://biblio.juridicas.unam.mx/libros/5/2212/13.pdf>, (fecha de consulta: 23/02/2016). El decreto que establece esto es el "544 de 1888", firmado por el presidente de la República, Rafael Núñez, y por el ministro de Instrucción Pública, Julio Casas Rojas. Recordemos que también esto fue parte del contrato celebrado entre este gobierno y el Vaticano. BNC, Registro de Bolívar, 23 de agosto de 1888, Cartagena. Revista Escolar, 31 de octubre de 1888, Cartagena. 
miembros de la administración pública en los no se vislumbre la preocupación por instruir a los distintos grupos sociales; un principio muy característico de la gran mayoría de los países de América Latina a lo largo y ancho del siglo XIX en el proceso de formación de Estadosnación. En plena sesión de la Asamblea departamental el gobernador de Bolívar, José Manuel Goenaga, les manifestaba a los diputados presentes lo que para él era la gran necesidad de Bolívar en esos momentos. En su discurso recalcaba, incluso con muchos signos de preocupación:

\footnotetext{
[...] reconstruida la Nación bajo la forma unitaria requerida por las nuevas instituciones, quedaron limitadas las funciones de las asambleas departamentales á puntos importantísimos de administración que no pueden ser descuidados sin perjuicio para el progreso del país. Honorables diputados propender al desarrollo de la industria en todas sus manifestaciones y al mejoramiento de las vías de comunicación equivale a emancipar a los pueblos de la miseria que los abruma. Pero fomentar y generalizar la instrucción con sujeccion a los principios de la moral cristiana, equivale a levantar la sociedad sobre las bases inconmovibles del deber y del derecho, fuera de las cuales no hay ni puede haber bienestar estable. ${ }^{9}$
}

Estas líneas sugieren la receptividad que tendrá en Bolívar la educación de carácter religioso impulsada desde el centro del país. Tan es así que promover la instrucción bajo parámetros de moral cristiana como prerrequisito para la adquisición de derechos y deberes, será un aspecto central para crear y mantener sólidas bases republicanas. En otro informe que presentaba el gobernador del Departamento en 1898, Eduardo Gerlein, al ministro de Instrucción Pública, le manifiesta con aire de estricta obligación y necesidad que "educar al pueblo para su gobierno, es el problema de la generación presente, y el ideal que persiguen los hombres que ven la grandeza de la patria en la cultura de sus hijos". ${ }^{10}$ Al mismo tiempo, el inspector de instrucción pública, Arturo Bermúdez, le señalaba al secretario de gobierno que "la instrucción primaria debe ser para el Estado objeto fundamental de particular atención, porque el desarrollo intelectual de las masas es la fuerza progresiva de las sociedades que las impulsa hacia la cima de sus aspiraciones". "En síntesis, fomentar la enseñanza pública se convirtió en un aspecto central en las preocupaciones de los conservadores durante todo el periodo de estudio. En su imaginario concebían que "la propagación de la instrucción pública es una de las necesidades de primer orden porque es menester que los ciudadanos todos estén en capacidad de seguir con interés el curso de los negocios públicos y porque como todos sabemos con la instrucción desaparecen los principales inconvenientes que dificultan

\footnotetext{
${ }^{9}$ BNC, Registro de Bolivar, 8 de agosto de 1888, Cartagena.

${ }^{10}$ BNC, Registro de Bolivar, 19 de agosto de 1898, Cartagena.

${ }^{11}$ BNC, Registro de Bolívar, 26 de diciembre de 1896, Cartagena.
} 
el progreso de la patria". ${ }^{22}$ En este sentido y para ambos proyectos estatales centrales en la historia política de Colombia durante todo el siglo XIX, la instrucción pública es una preocupación neurálgica en sus distintos programas modernizadores y, en efecto, representa una continuidad para tales estamentos públicos, pues, a pesar de que resolvían sus desavenencias mediante guerras civiles, fomentar la educación fue un puente de unión entre uno y otro. Al respecto señalaba un medio periodístico:

[...] en este siglo de luchas y disensiones verdadera época de transición en que todos buscan la cumbre por diversos medios y en que se cuentan tanto ideales como individuos diferentes hay una sola cuestión en que todos están conformes: la importancia de la educación y de la instrucción bien entendidas, la necesidad de mejorar en todos los sentidos las Escuelas, el deseo de dignificar y elevar moral y materialmente el profesorado. $^{13}$

Es decir, mucho más allá de las distancias hay ciertas coincidencias en el lugar de la educación, la escuela y el maestro, como ya lo veremos, porque tal como lo plantea un conocedor del tema, "con todos sus errores y carencias, el sistema educativo del radicalismo fue heredado por el personal político de la Regeneración e introdujo las modificaciones sustanciales para consolidar un sistema escolar confesional católico" (Loaiza, 2011: 329). Ahora nos detendremos en el papel que cumplen la escuela pública y la Escuela Normal Nacional de Bolívar en el proceso de formación de ciudadanos modernos. Reflexionar sobre esta representación en el contexto objeto de estudio es nuestro interés en las páginas que siguen.

\section{Escuela y ciudadanía en el Bolívar Grande}

Una vez finalizado el proceso de independencia en Colombia y en la gran mayoría de los países hispanoamericanos, un elemento que captó la atención de los dirigentes políticos denominados liberales o conservadores en su proyecto de construcción nacional fue la creación de mecanismos destinados a formar ciudadanos capaces no sólo de detentar la nueva legitimidad, sino también de funcionar en concordancia con el nuevo estilo urbano de vida que se estaba deseando como emblema de la soñada civilización. Había que crear la nación y en especial formar a los actores y los escenarios que sirvieran de base para su existencia. Tal como lo señala François Xavier Guerra: "del ciudadano podríamos decir lo que Tertuliano decía del cristiano. No nace se hace. Ser y sentirse ciudadano no es algo "natural", sino el resultado de un proceso cultural en la historia personal de cada uno y en la colectiva de una persona" (González Stephan, 1995: 432-433; Guerra, 1999: 33).

\footnotetext{
12 BNC, El Gladiador, 30 de abril de 1889, Cartagena.

${ }^{13}$ BNC, El Maestro de Escuela, 20 de enero de 1899, Bogotá.
} 
Una herramienta que se utilizó durante todo el siglo XIX, tanto en Colombia como en la gran mayoría de los países de América Latina, en las pretensiones de crear ese ciudadano necesario en la república, fueron precisamente la escuela de primeras letras y las escuelas normales. Para Sol Serrano es en estos espacios escolares donde se expande la cultura escrita y donde se funda la opinión pública, pero sobre todo donde la tendencia era "moralizar o más exactamente racionalizar los hábitos de los sectores populares. Ello como requisito previo a la ciudadanía política. La escuela debía ser un nuevo espacio físico, un microuniverso que introdujese a los alumnos a un nuevo concepto del espacio y del tiempo, del uso y del control del cuerpo, un espacio normativo diferenciado del espacio doméstico y comunitario" (Serrano, 1998: 351). En efecto, fue durante el periodo liberal y regenerador que el ideal de asumir la escuela como espacio excepcional en la formación de los nuevos hombres, tomó un interés central. Este escenario se constituye en el lugar privilegiado de los dirigentes políticos del país en las tres últimas décadas del siglo XIX con el fin de construir un individuo en estrecha correspondencia con las demandas políticas y sociales que requiere el mundo republicano que se aspiraba conquistar y edificar. Para Gilberto Loaiza, a pesar de las diferencias sobre el papel que cumple la escuela, entre los Ilamados moralistas católicos (conservadores) y los moralistas republicanos (liberales), estos lugares son para ambos el epicentro de la puesta en marcha de sus objetivos políticos. Es decir, "el proyecto del liberalismo radical de civilizar mediante la escuela, del moldear a los individuos, de volverlos sujetos controlados y autocontrolados, no fue - en últimas - muy distinto del proyecto educativo conservador que buscaba, del mismo modo, controlar moralmente a los individuos, garantizar la permanencia de la tradicional y mayoritaria adhesión a la religión católica" (Loaiza, 2011: 379).

En el Bolívar Grande, a partir de 1870 también se asume la escuela con el mismo ideal, y evidencia una continuidad entre liberales radicales y regeneradores por lo menos en este espacio geográfico. El Decreto orgánico de instrucción pública (DOIP) —creado por los primeros en 1870 y que, dicho sea de paso, marcó un antes y un después en la historia de la educación en este territorio por las profundas reformas que realizó en este campo— ${ }^{14}$ y el

\footnotetext{
${ }^{14}$ Decreto que, como su nombre lo indica, hace referencia a la promulgación de principios desde la misma raíz del elemento educativo; es decir, fue una disposición integral de todos los asuntos inherentes a la instrucción pública. Constaba de 10 capítulos y 294 artículos en los que se establecía la instrucción pública y gratuita dentro de un sistema uniforme dirigido y supervisado por el gobierno federal. Además, se describía la naturaleza de la enseñanza y la preparación de maestros. Establecía una dirección general primaria, como la oficina central de administración. Dividió la instrucción pública en tres grandes ramos: la enseñanza, la inspección y la administración. Creó la figura del Director General de Instrucción Pública, uno de manera central para todo el país y para cada uno de los estados que conformaban la Unión Colombiana. También se establecieron los métodos de enseñanza, los reglamentos en las escuelas, que incluían la parte de la disciplina, castigos, asistencia de los niños y premios, creación de escuelas normales en cada uno de los estados y la instauración de bibliotecas públicas, entre otros aspectos. Esta reforma abarcó todos los niveles educativos -primaria, secundaria y nivel universitario- y le otorgó a la educación un sentido gratuito y obligatorio. Cuestión sui generis en el país y que sin duda marcó un antes y un después en la historia educativa de Colombia, ya que toda la legislación anterior había definido la educación como gratuita pero no obligatoria.
} 
reglamento que reorganiza la instrucción pública en este territorio durante la Regeneración en 1886 cuando estos últimos retornan al poder luego de su victoria en la Guerra de la Humareda, vislumbran la importancia de la escuela para constituir ciudadanos y generar en ellos valores, así como ilustración para el trabajo. Para ambos proyectos políticos, a pesar de sus diferencias, "las escuelas tienen por objeto formar hombres sanos de cuerpo i de espíritu, dignos i capaces de ser ciudadanos i magistrados de una sociedad republicana i libre [...] la enseñanza en las escuelas no se limitará a la instrucción, sino que comprenderá el desarrollo armónico de todas las facultades del alma, de los sentidos i de las fuerzas del cuerpo [...] las escuelas deben funcionar de suerte que de su labor resulte freno moral, instrucción eficaz y ocupación constante". ${ }^{15}$ Lo anterior permite señalar que el espacio escolar es el lugar propicio para modelar a los nuevos hombres, traspasar la simple enseñanza de acumulación de saberes hacia una más integral con fuertes principios moralistas e instrumentalizada para desempeñar algún oficio; importante función social y política, que hará de las escuelas establecimientos muy asociados a la búsqueda del progreso. En el ambiente político de todos estos años existió una fe ciega en la escuela como herramienta para transformar a la sociedad hacia niveles de desarrollo nunca antes experimentados en Bolívar.Las escuelas son, entonces, establecimientos sociales de gran relevancia en este territorio, el teatro que construye y donde se apropian de valores el futuro funcionario de la administración pública, los encargados de legislar la justicia, el potencial elector y todo individuo que se proyecta cobijar bajo este cielo ilustrado. ${ }^{16}$ En efecto, se conciben la educación pública y tales establecimientos como herramientas esenciales para ilustrar al pueblo y formar ciudadanos que estén en concordancia con los principios republicanos y no se dejen arrastrar por las pasiones del desorden social y mucho menos por la intolerancia que genera violencia. Tanto liberales como regeneradores concibieron estos campos para reproducir su discurso político de mantenimiento del orden y el progreso, pero también para que el individuo y los grupos sociales se apropien de instrumentos para su propia sobrevivencia. De nada valían las disertaciones si no despuntaban en mejorar las profundas demandas políticas, sociales y culturales que ofrecía el mundo que los rodeaba. Con base en los planteamientos de Lucia Lionetti para el caso de Argentina a fines del siglo — cuyo paralelo reafirma lo que venimos expresando para el Bolívar Grande-, "la escuela pública se convirtió en una institución sobre la que se depositó una serie de valoraciones positivas y expectativas. La política educativa y quienes estuvieron involucrados en su ejecución buscaron una educación integral que desarrollaría las

${ }^{15}$ BNC, La Escuela Normal, 21 de enero de 1871, Bogotá, p. 4. Registro de Bolívar, 10 de diciembre de 1886, Cartagena. Registro de Bolívar, 24 de agosto de 1886, Cartagena. Gaceta de Bolívar, 4 de febrero de 1872, Cartagena. Revista Escolar, 15 de marzo de 1890, Cartagena. Diario Oficial, 12 de febrero de 1893, Bogotá, p. 196. Revista de la Instrucción Pública de Colombia, 10 de febrero de 1893, Bogotá, p. 94.

${ }^{16}$ Archivo Histórico de Cartagena (en adelante AHC), Gaceta de Bolivar, 9 de septiembre de 1874, Cartagena, p. 201. 
capacidades físicas, intelectuales y morales de los alumnos, pretendiendo fijar un universo de valores sobre los que se cimentara la naciente comunidad"17 (Lionetti, 2005: 1230).Si la escuela pública era concebida como el espacio privilegiado en la formación de los nuevos ciudadanos modernos que requerían el país y el territorio bolivarense, el primer ciudadano de esa república, tanto para liberales como para regeneradores, no era otro que el maestro de primeras letras formado en la Escuela Normal Nacional de Bolívar, ${ }^{18}$ quien además tenía el importante papel de poner en práctica sus reformas a la enseñanza y ayudar a la popularización de la instrucción pública, pero sobre todo era quien encarnaría el modelo de ciudadanía "ideal". Para estas élites políticas de nada serviría la puesta en marcha del fomento de la educación pública para todas las clases sociales y hacer significativos esfuerzos por invertir en este campo, sin el acompañamiento incondicional del maestro y, en menor medida, de las maestras. El primer paso fue la llegada, en 1872, de un grupo de pedagogos extranjeros especialmente alemanes. Los directores de estos centros educativos debían impartir la enseñanza con los modelos pedagógicos de Pestalozzi. Fueron nueve los profesores que en la década de 1870 arribaron a nuestro país: "Gottol Weis en el Estado de Antioquia, Julio Walner en Bolívar, Augusto Pankau en Cauca, Carlos Meisel en Magdalena, Ofiold Wirsing en Panamá, Alberto Blume en Cundinamarca, Gustavo Radlack en el Tolima, Ernesto Hotschick en Boyacá y Carlos Uttermann en Santander". 19 Tanto la creación de las escuelas normales como la llegada de estos profesores alemanes, siete de religión protestante y dos católicos, recibieron la fuerte oposición de los conservadores en este territorio, los cuales planteaban "que era una usurpación intelectual o la amenaza de un estado moderno que se seculariza o una conspiración para enviar protestantes" (Loaiza, 2011: 350). De hecho, estados como Tolima y Antioquia por clara tendencia conservadora sólo recibieron a los pedagogos de afiliación católica. En los otros espacios geográficos los que llegaron fueron aceptados aunque con algunas hostilidades, particularmente en Magdalena y Cauca. Lo paradójico del asunto es que las escuelas normales no cerraron definitivamente cuando llegaron los regeneradores al poder, después de 1886, y Bolívar no fue la excepción, pues las escuelas normales se mantuvieron muy presentes durante toda su hegemonía hasta el punto de promover la llegada de

${ }^{17}$ Para el caso de la Ciudad de México un estudio sugestivo que da cuenta del papel de la escuela en este escenario es el de Josefina Granja (2009: 217-254).

${ }^{18}$ En este artículo nos centramos exclusivamente en la Escuela Normal Nacional de Bolívar y en la Escuela Normal de Institutores, con sede en la provincia de Cartagena entre 1870-1899.

${ }^{19}$ BNC, La Escuela Normal, 18 de enero de 1873, Bogotá. La dirigencia liberal tiene la perspectiva de no seguir dinamizando enemistades con la Iglesia católica y los conservadores. En el contrato que realiza el cónsul de Colombia en Alemania con estos pedagogos extranjeros, en su mayoría de religión protestante, queda establecido que "cualesquiera que sean los resultados en la dirección de las Escuelas Normales por profesores alemanes los documentos de que se deja hecha mención comprueban, por una parte que lo que se propuso el gobierno que los hizo venir fue exclusivamente mejorar la educación popular i no acatar culto relijiosos i por otra parte que el mismo Gobierno tomo cuantas precauciones podían aconsejarle el patriotismo i la prudencia". BNC, La Escuela Normal, 18 de enero de 1873, Bogotá. 
profesores, pero de nacionalidad española. ${ }^{20}$ Pronto este plantel se convirtió en un establecimiento modelo en el Bolívar Grande, no sólo por los beneficios que se empezaron a recibir con el método de enseñanza utilizado, sino también por la calidad de sus egresados y su posicionamiento en las diversas escuelas públicas en todo el Estado. Lo que se percibe durante toda la época objeto de estudio es la materialización de los buenos resultados en la instrucción oficial gracias a la utilización de los modernos procedimientos pedagógicos, pero sobre todo por observar en los espacios escolares a los maestros ya graduados cumpliendo su tarea por la cual fueron formados en la Escuela Normal..$^{21}$ Durante este periodo hubo una estrecha relación entre escuela y ciudadanía, un imaginario que veía en estos espacios los escenarios donde se formarían los ciudadanos que debían habitar la República para lograr de esta manera no sólo la popularización de la instrucción sino también una tendencia por el adelanto de la sociedad, que más tarde consolidaría el engrandecimiento de la patria. La idea era construir un ciudadano en cuya vida pública y privada fuera un modelo de persona, respetuoso, ilustrado, cívico, bondadoso y con todas las virtudes inherentes al aparato de valores que hay en la sociedad. Ahora abordaremos un aspecto clave en la manera de concebir al maestro egresado de la normal: el modelo de ciudadano. Para los grupos denominados liberales y conservadores, el egresado de este plantel no sólo sería el formador de ciudadanos o quien ayudara a popularizar la instrucción pública, sino que, en ese proceso de construir ciudadanía él sería al mismo tiempo el modelo a seguir por los niños y por la sociedad en general. Nuestro interés en las páginas que siguen es reflexionar sobre esta representación en el contexto objeto de estudio.

\section{Maestro: modelo de ciudadano "ideal"}

Cuando uno observa el Decreto Orgánico de Instrucción Pública creado por los liberales en 1870 y el reglamento que reorganiza, por parte de los regeneradores, la instrucción pública en el Bolívar Grande en 1886 podemos analizar no sólo el momento en que en nuestro país se empezó a modernizar la enseñanza y popularizarla, a disciplinar a los individuos y controlarlos con el uso del tiempo en los espacios escolares, a utilizar las escuelas como los lugares donde se forman los ciudadanos modernos como ya hemos visto, sino también lograr que la labor del maestro de escuela formado en la normal sea una profesión modelo de la sociedad,

\footnotetext{
${ }^{20}$ Los conservadores justificaron la permanencia de las escuelas normales porque para ellos "debe darse toda la preferencia posible a los centros educativos, de donde más tarde tiene que salir el diligente obrero de la juventud y que de esa escuela ha de partir el bienestar general”. BNC, Revista de la Instrucción Pública de Colombia, junio de 1894, Bogotá. Revista de la Instrucción Pública de Colombia, enero de 1893, Bogotá.

${ }^{21}$ Una semblanza de lo anotado puede verse en BNC, Registro de Bolívar, 2 de noviembre de 1895, 10 y 12 de agosto de 1898, 27 de julio de 1899, 16 de septiembre de 1899, Cartagena; BNC, Diario de Bolívar, 17 de noviembre de 1876, 19 de enero de 1879, Cartagena.
} 
como quizás nunca antes se había concebido en el seno de las sociedades colombiana y bolivarense. Esta ideología se hizo presente en las páginas, de ambos tratados educativos. En estos decretos oficiales se reafirmaba lo siguiente:

El director de la escuela por la importancia i santidad de las funciones que ejerce es el principal funcionario del distrito, i tiene el deber de arreglar su conducta de manera que en su vida pública i privada sirva de tipo a todos los ciudadanos. Debe estar sostenido i animado por un profundo sentimiento de importancia moral de sus funciones, i fundar su principal recompensa en la satisfacción de servir a los demás hombres i de contribuir al bien público [...] será pundonoroso, leal en sus relaciones, benévolo i afable en sus trato, cumplido en sus maneras. [...] en ningún caso se dejara arrastrar a efectos de pasión, ni incurrirá en otra debilidad que pueda comprometer su carácter, el cual debe formar un conjunto de virtudes varoniles. [...] las faltas contra el pudor, la temperancia, la moderación, el aseo, así como todo abuso patente en su vida doméstica, de la autoridad del padre, marido, jefe de familia, serán castigadas en un maestro de escuela con la pérdida del empleo. Le está prohibido el roce con personas reputadas de mala conducta i la frecuentación de tabernas casas de juego, no ponerse ni en una ocasión en estado de embriaguez; no estar nunca en pendencias ni dar escándalos; no apartarse ni un punto en fin de las buenas costumbres, no fumar jamás en presencia de los alumnos [...] las autoridades dispensaran a los directores de escuela una consideración especial i una deferencia respetuosa, en atención al augusto ministerio que desempeñan. ${ }^{22}$

En efecto, las sociedades colombiana y bolivarense asistieron en las tres últimas décadas del siglo XIX al fomento del ideal que veía al maestro como el prototipo de ciudadano. Por ello los esfuerzos por parte de los grupos denominados liberales y conservadores en el sentido de que fuera el sujeto central en la administración pública, pero además el modelo de ciudadano ya que le correspondía no sólo ser espejo ante todos por sus virtudes, sino que su vida tanto pública como privada debía estar siempre en estrecha relación con principios morales y honorables. No solamente estaba en juego su buena notoriedad, sino que ante todo tenía que velar por mantener su trabajo ya que ante una falta en contra de lo que no le era permitido era justa causa para relevarlo de su cargo. En otras palabras, para ambas élites políticas él era la personificación real y viva del verdadero ciudadano, idealizado si se quiere desde la prensa instruccionista y oficial, pero a lo que asistimos durante toda la época objeto de estudio es a la representación sistemática del maestro como sujeto central en la popularización de la enseñanza y paradigma de la ciudadanía, además de figura social que reproducirá

22 BNC, La Escuela Normal, 7 de enero de 187, 5 de septiembre de 1874, 18 de enero de 1873, Bogotá. Registro de Bolívar, 1 de septiembre de 1886, 8 de octubre de 1886, 17 de junio de 1886. Registro de Bolívar, 20 de octubre de 1898, 10 de diciembre de 1886, 9 de julio de 1898, Cartagena. Revista Escolar, 15 de marzo de 1890, Cartagena. Revista de Instrucción Pública, febrero de 1896, Bogotá. Revista de Instrucción Pública de Colombia, julio de 1893. 
el eco de las virtudes republicanas en el proceso de formación del Estado-nación en Colombia y su región Caribe; asunto neurálgico que constituye, a la par de la preocupación por la educación pública y las escuelas como epicentro en la formación de ciudadanos, otro elemento de continuidad entre el liberalismo radical y la regeneración en esta parte del territorio nacional.

En los diarios y en la prensa instruccionista de la época casi no hay página donde no se vislumbre el ideal que concibe al maestro como modelo de vida en la sociedad. En esa prensa aparece usualmente lo siguiente: "El Maestro, como el sacerdote, ha de ser en la población en que ejerza sus funciones, un modelo de buena conducta, porque como aquel, tiene una misión elevada la de llevar la práctica de la virtud al seno de los hogares. El institutor debe evitar cuidadosamente la intimidad con personas de no mui bien sentada reputación. La sociedad que él frecuente, dará la medida de sus instintos morales i de la estimación en que tiene su carácter i la elevada misión que se le ha encargado". 23 Estas líneas dan luces precisamente del carácter moral y cívico que un maestro debía poseer. En las provincias, distritos y municipios de Bolívar el maestro no podía perder de vista ese imaginario. Una cuestión que siempre se le pedía era enseñar con el ejemplo. Sí existía pleno compromiso por vigilar la conducta de los niños dentro y fuera de la escuela. La mejor carta de presentación de "un institutor será el buen comportamiento que observen sus alumnos fuera de la escuela". ${ }^{24}$ Por eso la comparación con el sacerdote, que era también para la época ejemplo de virtudes y de buena conducta pública y privada. Debía transmitir confianza y firmeza de carácter, pero además sus actuaciones incumbían muestras integrales en su vida personal porque sin duda los ojos de todos estaban directa o indirectamente sobre sus actuaciones.

Existía pleno compromiso por vigilar la conducta de los niños no sólo dentro, sino fuera de la escuela; la mejor carta de presentación de "un institutor será el buen comportamiento que observen sus alumnos fuera de la escuela." 25 En definitiva, para la élite liberal y regeneradora "el maestro debe ser un modelo para sus alumnos. Tanto en su vida pública y privada" ${ }^{26}$ Algo que siempre se le pedía al maestro y que fue recurrente en todos los años objeto de estudio era que debía

${ }^{23}$ BNC, La Regeneración, 26 de agosto de 1878, Cartagena.

${ }^{24}$ En otra nota se afirmaba "que enseña el maestro no solo por lo que dice y hace, sino en gran parte también con lo que es". Revista Escolar, 15 de marzo de 1890, Cartagena, p. 260. Revista Escolar, 18 de febrero de 1878, Cartagena, p. 3. Revista de Instrucción Pública de Colombia, marzo de 1894, Bogotá, p. 103.

${ }^{25}$ En otra nota se recalcaba "que enseña el maestro no solo por lo que dice y hace, sino en gran parte también con lo que es". Revista Escolar, 15 de marzo de 1890, Cartagena. Revista Escolar, 18 de febrero de 1878, Cartagena. Revista de Instrucción Pública de Colombia, marzo de 1894, Bogotá.

${ }^{26}$ Se insistía, además, en que "El Maestro debe unir al precepto el ejemplo, teniendo siempre presente que su influencia sobre sus discípulos durará aún después que estos hayan cambiado los deberes de la Escuela por los complicados problemas de la vida". BNC, El Maestro de Escuela, 20 de julio de 1899, Bogotá. 
amar su profesión considerando que los efectos benéficos de su trabajo son los más duraderos i de importancia que sobre los bienes de la libertad dan a la vida del hombre su valor i su perfume; que si Fidias i Miguel Anjel trabajan el mármol frio él tiene el poder de amoldar corazones palpitantes i dirijir inteligencias inmortales; que mejor que Handel i Mozart él tiene que tocar un instrumento mucho más complicado, cuyas cuerdas son susceptibles cada una de mil tonos, que si los héroes destruyen el crea, que si ellos conquistan la tierra; él conquista el dominio del alma, que si los estadistas gobiernan los imperios i dan leyes a la propiedad; el enseña a gobernar esos imperios i da leyes a el alma ${ }^{27}$

La vocación y el amor a su ejercicio pedagógico eran variables que debían ir de la mano del maestro. Lo que él proyectaba y transmitía a sus alumnos constituía una de las bases para enfrentar múltiples y complejas demandas sociales y políticas que la sociedad republicana reproducía. Llama mucho la atención el carácter metafórico de lo señalado para sugerir la durabilidad en la formación que se adopta por parte del maestro. Su misión era educar a los distintos individuos para pensar y construir un universo mental en los niños que los volviera críticos y seres pensantes, pero sobre todo había la exigencia de enseñar para la vida y para ejercer algún tipo de oficio. Por eso, una regla básica que esta figura social no podía perder de vista en su vida profesional y personal era precisamente la de

Ser modelo de virtud, de decoro y buenos modales y procurar de un modo persistente que sus alumnos adquieran hábitos en ese mismo sentido; tener siempre presente que las cualidades del agente determinan el carácter y los resultados de la obra, que el maestro de escuela como el sacerdote y el hombre de estado ha de obrar sobre el espíritu y la conducta de sus subordinados; que a la larga nada influye tanto sobre la conducta como la conducta misma; que como la enseñanza el agente o gobernante se halla en más inmediato contacto con los gobernados, que en cualquiera otra profesión o situación social. El influjo de su conducta tiene que ser más eficaz; y que el maestro no solo enseña por medio de lo que dice, sino por medio de lo que hace. Por medio de lo que es [...] un maestro de malas costumbres e ineptos jamás podrá hacerse amar y respetar [...] como el maestro así es la escuela. Y como las maneras que tanto influjo tienen en la vida del hombre y tan capital importancia deben tener por consiguiente en la educación se adquieren principalmente imitando lo que en la niñez

\footnotetext{
${ }^{27}$ Además, se señalaba que "la carrera de institutor requiere una vocación especial. el que la toma por lucro hace un mal cálculo i no desempeñara sus funciones con el espíritu que ellas exijen [sic] para obtener buenos resultados. abraza esta carrera con verdadera vocación el que sobre toda consideración personal i habiendo medido ante las dificultades i comprendido cuanto valor se necesita para vencerlas, siente no obstante decidida inclinación, hacia ella; ama a los niños, gusta de estar en medio de ellos, no le fastidia su aturdimiento, ni le desalienta su ignorancia". BNC, La Escuela Normal, 15 de agosto de 1874.
} 
se ve, el maestro que en todo debe ser ejemplo de sus alumnos debe serlo también de buena maneras. ${ }^{28}$

Hay en este ambiente instruccionista la muy estrecha relación en la representación de hacer del maestro el modelo de ciudadanía "ideal". Para la dirigencia liberal y regeneradora tal perfil no encajaba en otra persona más que en el institutor. Se reitera la similitud que debía de poseer, en términos de buena conducta pública y privada, tanto con el sacerdote como con el jefe de Estado y aquí esta representación cobra vida para ambos periodos, quizás mucho más fuerte durante la Regeneración. Su imagen incluso debía ser mucho más decorosa que cualquier otro funcionario de la administración pública porque de ahí dependían el respeto de todos los grupos sociales hacia su persona y la buena recepción de la enseñanza en los niños de la cual sin duda alguna "depende la victoria de la civilización sobre la barbarie [...] pues deplorable seria el estado de nuestras naciones sin el maestro, sumidos todos en la oscura y sombría noche de la ignorancia." ${ }^{29}$

El maestro se constituye en sujeto central tanto en el proyecto educativo liberal como en el regenerador. Su privilegiado lugar en este escenario se convierte en algo sui generis en la historia política de nuestro país y, por supuesto, en esta parte del Caribe colombiano. Como ya se ha mencionado, igual que el sacerdote el maestro tenía el importante papel de instruir a los nuevos ciudadanos que requería la república; prepararlos moralmente y con clara conciencia de sus deberes y derechos para que no se dejaran manipular en sus haberes políticos; formar al niño de manera exhaustiva, para honra de su familia, la patria y la sociedad en general. En última instancia el maestro era el individuo que personificaba al verdadero intelectual que promovieron los dirigentes decimonónicos para consolidar con mucha más fuerza sus proyectos públicos de Estado y sus distintas formas de hacer y construir sociedad; por supuesto, sin perder nunca de vista la imagen de paradigma de la ciudadanía.

Era tal el peso y el significado que incluso para la élite conservadora los maestros y el fuero eclesiástico eran los encargados precisamente de acompañar de manera central el proceso de "regenerar" a la sociedad colombiana a partir de 1886. Así lo reflexiona uno de los principales dirigentes de este partido, el cartagenero Rafael Núñez, al asumir el nombramiento de presidente electo:

\footnotetext{
${ }^{28}$ BNC, Registro de Bolívar, 31 de agosto de 1886, 31 de agosto de 1886, Cartagena. Se reproducía también que no había "oficio más elevado que el de maestro de la juventud, porque nada hai más precioso en la tierra para la mente, el alma i el carácter del niño. ningún cargo u ocupación debe ser mirada con mayor respeto; i las primeras intelijencias de la comunidad debían recibir grandes estímulos para emplearse en ella. ojala los padres se propusiese sacrificar lo más posible de sus bienes reducirse a lo indispensable a cambio de inducir a esos personajes a ser guardianes i guas de sus hijos". BNC, La Escuela Normal, 5 de febrero de 1876, Bogotá. Registro de Bolívar, 24 de noviembre de 1898, Cartagena. Revista de la Instrucción Pública de Colombia, marzo de 1894, Bogotá.

${ }^{29}$ BNC, Registro de Bolivar, 26 de agosto de 1886, Cartagena. Revista de Instrucción Pública de Colombia, septiembre de 1894, Bogotá.
} 
Lo que importa mucho es que todos los que militamos bajo la modesta bandera de la Regeneración nos penetremos íntimamente de cuanto este vocablo significa. Algo semejante a un discurso religioso debe animar nuestros corazones de manera que no haya la menor duda de que estamos en todo caso dispuestos a sacrificar personales intereses por el triunfo de la idea general. Al propio tiempo tengamos cuidado de no volver los ojos como la mujer de Lot hacia la condenada Sodoma y aunque de sus almenas destruidas lancen sobre nuestras espaldas envenenados dardos sigamos imperturables en búsqueda de los horizontes ya entrevistos por el instinto popular. De antemano pues se comprende el espíritu moral de la Regeneración y corresponde al clero y a los profesores y maestros y sobre todo a los conductores políticos con grandes ejemplos de abnegación, la tarea de dar encarnación a ese espíritu de la obra emprendida. Lo cual no es obra aislada y caprichosa sino la que debe ejecutarse en la carrera del siglo XIX para desencantarse de las brillantes y seductoras promesas que le hicieron a fines del siglo anterior los filósofos y economistas lisiados de miopía. ${ }^{30}$

En este escenario será frecuente que la misma prensa instruccionista haga llamados al conjunto de la sociedad colombiana y bolivarense sobre la necesidad no sólo de instruirse sino también de ver en el maestro el principal personaje público de la provincia, el distrito y el municipio con mucha responsabilidad social, pero poseedor sobre todo de virtudes y modelo de las mismas. En él estaban guardadas todas las esperanzas para dejar atrás la "barbarie" e iniciar el camino del progreso y la "civilización". Su papel era tan privilegiado que dé él dependía hasta la propia consolidación de la república. ${ }^{31}$

En síntesis, la preocupación por la instrucción pública, la utilización de las escuelas de primeras letras y la normal son el teatro para la formación de ciudadanos modernos y, en la inquietud por hacer del maestro el modelo de ciudadano "ideal" tanto para liberales como para regeneradores, es donde descansará una buena parte de su proyecto educativo y político moderno; variables que, sin querer ser repetitivos, se convierten además en puentes de unión para estos estamentos públicos, algo desconocido por cierta historiografía. Al realizar un análisis comparativo con México, durante la época del Porfiriato y siguiendo los planteamientos de Mílada Bazant, la importancia del maestro era tal en este escenario que "así como el notario, el maestro cumplía, además de su profesión, una función pública porque su trabajo afectaba a la sociedad entera. El cargo del maestro era como el del sacerdote, cuya virtud esencial era la vocación de servir a los demás. El maestro era un santo de la democracia, que había que poner en el altar" (Bazant, 1993: 142), lo que nos permite construir un diálogo de relación con otras realidades latinoamericanas y poner en el acento de la reflexión los varia-

\footnotetext{
30 BNC, La Bandera Nacional, 9 de septiembre de 1897, Cartagena.

${ }^{31}$ BNC, La Escuela Normal, 8 de julio de 1872, Bogotá.
} 
dos y múltiples colores que representó el maestro de primeras letras en el universo educativo y político bolivarense.

\section{Conclusiones}

Un editorial de un periódico de ideología conservadora reproducía las múltiples diferencias que, según esta prensa, separan a su partido del grupo político de los liberales radicales. Señalaba que, si bien tenían sus desavenencias respecto a libertades individuales, virtud ciudadana o modelo de virtud católica, centralismo o federalismo político, proteccionismo o liberalización económica, o respecto a distintas maneras de pensar y concebir la sociedad, era en el papel que le otorgaban a la religión donde se acentuaba la diferencia entre ambos proyectos políticos. Enfatizaba: "[...] hoy la cuestión religiosa es el grande y profundo abismo que separa al conservatismo del radicalismo. Si no se hubiera mezclado a la política esta grave cuestión tal vez no hubiera habido en Colombia tantas revoluciones". ${ }^{32}$

Es muy ilustrativo este discurso porque en él se expresa lo que distanciaba a un grupo del otro. En efecto, y contrario a lo que superficialmente se presentaba como dos proyectos políticos radicalmente desiguales, asistimos a continuidades históricas entre uno y otro. En el caso que nos interesa analizar, estas continuidades fueron en el fomento de la educación pública, en hacer de las escuelas tanto de primaria como normales los espacios privilegiados para la formación de los futuros ciudadanos modernos, y en la representación que hacen del maestro de escuela primero como figura central en la instrucción popular, intermediario principal entre el Estado y la sociedad, y paradigma en la ciudadanía, Estas las variables que nos permiten observar una profunda prolongación en el Bolívar Grande entre grupos de liberales y regeneradores entre 1870-1899.

Muy a pesar de esto es importante tener en cuenta que liberales y regeneradores respondieron de igual manera a distintas formas de implantar sus dispositivos educativos y, por ende, de concebir al maestro durante esta plataforma republicana y pública, sobre todo en el lugar que ocupará en términos de relaciones con la Iglesia católica. Tal como lo ha planteado el historiador Gilberto Loaiza desde una visión "nacional", es también el maestro -y añadiría la educación - durante todo el siglo xIX elemento central "de un forcejeo entre proyectos de definición de la nación" en el que la élite política de ambos partidos no estará exenta de esas disputas republicanas (Loaiza, 2011:353).

En efecto, durante el liberalismo el maestro era el intelectual laico que también formarían las escuelas normales a lo largo y ancho del país "en oposición a la tradicional influencia del

\footnotetext{
32 BNC, El Obrero, 15 de marzo de 1891, Cartagena, p. 30.
} 
sacerdote católico, del tinterillo y del gamonal" (Loaiza, 2007: 64), figuras tradicionales en esa sociedad colombiana. Por tanto, este tópico se convirtió en una de las aspiraciones políticas de este grupo social. Es decir, un maestro envestido de valores laicos que en esta primera etapa de dominio liberal debía restarle importancia a esos personajes que materializaban usos consuetudinarios, en una sociedad que intentaba precisamente dejar atrás esas vetustas prácticas. Sin duda, esta representación también se sumará a los esfuerzos que esta élite hará por construir las bases de una sociedad moderna, secularizada y con una clara neutralidad religiosa, en donde el maestro también debe ocupar un papel central.

Si esto ocurrió durante el régimen liberal otra fue la realidad en el periodo de la Regeneración, pues lo que podemos analizar es que no existió una preocupación por sustraer la influencia del sacerdote en la sociedad y mucho menos que los maestros tuvieran ese tipo de representaciones. En el marco de un Estado centralizado, menos laico y mucho más de corte religioso, ambas figuras tendrían un diálogo permanente y la élite de este tiempo los concibió unidos desde sus variadas realidades, como dos figuras sociales clave para materializar su hegemonía política. No es gratuito que el cartagenero Rafael Núñez en sus múltiples discursos, cuando fue presidente de este territorio y uno de sus grandes abanderados, impulsara este tipo de influjos tras los Ilamados permanentemente a que ocuparan un lugar central en pensar y repensar el incipiente Estado-nación, así como la consolidación del proyecto educativo. En otras palabras, no existió esa separación incisiva entre maestros y curas que trataron de promover los liberales radicales, sino más bien una metamorfosis y una estrecha relación sin perder de vista sus distintos lugares sociales — parroquia, escuela - para avanzar hacia una sociedad moderna pero sustentada en principios tradicionalistas. Sólo así, uniendo fuerzas desde el fuero eclesiástico y el civil se haría el tránsito para "regenerar" los distintos grupos sociales y perfilar a Colombia y su región Caribe hacia el soñado y tan necesario progreso.

En fin, se trata de avanzar en este tipo de estudios que nos permiten dialogar desde la perspectiva regional sin perder de vista lo que ocurría a nivel nacional y en ciertos escenarios latinoamericanos, sobre todo para hacer ese fascinante diálogo entre el pasado y el presente. Muchos de los imaginarios y discursos que durante esta época se construyeron en torno al lugar de la educación y del maestro cruzan el periodo de estudio y desde mi perspectiva aún deberían mantenerse.

\section{Fuentes}

Archivos

AHC Archivo Histórico de Cartagena: Gaceta de Bolívar, Diario de Bolívar. 
BNC

Biblioteca Nacional de Colombia: La Verdad, La Regeneración, Registro de Bolívar, La Escuela Normal, El Gladiador, El Maestro de Escuela, Revista de la Instrucción Pública de Colombia, Revista Escolar, La Bandera Nacional.

\section{Bibliografía}

Acevedo, Ariadna (2011), "Muchas escuelas y poco alfabeto: la educación rural en el Porfiriato. México, 1876-1910", en Alicia Civera Acevedo, Juan Alfonseca y Carlos Escalante (coords.), Campesinos y escolares. La construcción de la escuela en el campo latinoamericano siglos XIX y XX. Miguel Ángel PorrúaEl Colegio Mexiquense, México, pp. 73-100.

Agulhon, Maurice (1989), Marianne au combat: l'imagerie et la symbolique républicaine de 1789 à 1880, Flammarion, París.

Alarcón Meneses, Luis, Jorge Conde Calderón y Adriana Santos Delgado (2002), Educación y cultura en el Estado Soberano del Magdalena (1857-1886), Fondo de publicaciones de la Universidad del Atlántico, Barranquilla, Colombia.

Amaro Peñaflores, René (2006), "La construcción de la ciudadanía en Zacatecas: las corporaciones artesanales y la instrucción para el trabajo en el siglo XIX”, Revista Investigación Científica, núm. 2, Zacatecas, UAZ

Andrade, Margot (2011), "Religión, política y educación en Colombia. La presencia religiosa extranjera en la consolidación del régimen conservador durante la Regeneración”, Historelo. Revista de Historia Regional y Local, núm. 3, abril, pp. 154-172.

Báez, Miriam (2004), Las escuelas normales y el cambio educativo en los Estados Unidos de Colombia en el periodo radical. 1870-1886, Universidad Pedagógica y Tecnológica de Colombia, Tunja.

Bazant, Mílada (1993), Historia de la educación durante el Porfiriato, El Colegio de México, México.

Berquist, Charles. (1977), "Una década de Regeneración, 1886-1896", en Jesús A. Bejarano (comp.), El siglo XIX visto en Colombia visto por historiadores norteamericanos, La Carreta, Medellín, pp. 115-174.

Cardona Zuluaga, Patricia (2001), "La escuela: el germen del Estado, el progreso y la civilización. La inserción de las ideas modernas en el Estado Soberano de Antioquia vistas desde los planes educativos de los liberales radicales y de la Regeneración. Un estudio comparativo. 1870-1890”, tesis de maestría, Universidad Nacional de Colombia, Sede Medellín.

Castro, Luis (2011), "Estado nacional y escuelas rurales en el espacio andino y pampino del norte de Chile (Tarapacá 1880-1930)", en Alicia Civera, Juan Alfonseca y Carlos Escalante (coords.), Campesinos y escolares: la construcción de la escuela en el campo latinoamericano (siglos XIX y XX), Miguel Ángel Porrúa, El Colegio Mexiquense, México, pp. 139-173.

Flórez, Roicer (2010), "El uso privado de la autoridad pública en el Estado Soberano de Bolívar, 18631878", tesis de maestría, Universidad Pedagógica y Tecnológica de Colombia en convenio con la Universidad de Cartagena, Cartagena.

González, Fernán (1979), Educación y Estado en la historia de Colombia, Centro de Investigación y Educación Popular (CINEP) (Serie Controversia), Bogotá.

González Stephan, Beatriz (1995), "Modernización y disciplinamiento. La formación del ciudadano: del espacio público y privado", en Beatriz González et al. (comps.), Esplendores y miserias del siglo XIX. Cultura y sociedad en América Latina, Monte Ávila, Venezuela, pp. 432-433. 
Granja-Castro, Josefina (2009), "Contar y clasificar a la infancia. Las categorías de la escolarización en las escuelas primarias de la Ciudad de México, 1870-1930", Revista Mexicana de Investigación Histórica, vol. 14, núm. 40, enero-marzo, pp.217-254.

Guerra, François-Xavier (1999), "El soberano y su reino. Reflexiones sobre la génesis del ciudadano en América Latina”, en Hilda Sábato (coord.), Ciudadanía política y formación de las naciones. Perspectivas históricas de América Latina, Fideicomiso Historia de las Américas (Serie Estudios), Fondo de Cultura Económica, México, pp. 34-61.

Jaramillo, Jaime (1982), "El proceso de la educación desde el Virreinato a la época contemporánea", Manual de Historia de Colombia, t. III, Procultura, Bogotá, pp. 230-250.

Lionetti, Lucía (2005), "La función republicana de la escuela pública. La formación del ciudadano en Argentina a fines del siglo XIx", Revista Mexicana de Investigación Educativa, vol. 10, núm. 27 pp. 1225-1255.

Loaiza, Gilberto (2007), "El maestro de escuela o el ideal del ciudadano en la reforma educativa de 1870", Revista Historia Crítica, núm. 34. Bogotá, Universidad de los Andes, pp. 62-91.

(2011), Sociabilidad, religión y política en la definición de la nación (Colombia, 1820-1886), Universidad Externado de Colombia, Bogotá.

Molina Hernández, Jorge (1999), "Las políticas de recatolización en la Provincia de Cartagena, 18781898", tesis para optar al título de historiador, Universidad de Cartagena, Colombia.

Ortiz, Luis J. (2005), "Guerras civiles e Iglesia católica en Colombia en la segunda mitad del siglo XIX", en Luis Javier Ortiz Mena et al., Ganarse el cielo defendiendo la religión. Guerras civiles en Colombia, 1840-1902, Universidad Nacional de Colombia-Unibiblos (col. Textos), Bogotá, pp. 47-82.

(2009), "La regeneración en Colombia, 1878-1902", en Diana Bonnet, Michael LaRosa y Mauricio Nieto (coords.), Colombia: preguntas y respuestas sobre su pasado y presente, Universidad de los Andes, Bogotá, pp. 231-254.

Pacheco, Berena y Libis Castellanos (2010), "La educación durante la Regeneración en Cartagena 18851895", tesis de grado para optar al título de historiadora, Universidad de Cartagena, Colombia.

Palacios, Marco (2002), "La Regeneración en el espejo liberal y su importancia en el siglo xx", en Rubén Sierra Mejía (ed.), Miguel Antonio Caro y la cultura de su época, Universidad Nacional de Colombia, Sede Bogotá, pp. 261-278.

Rausch, Jane (1993), La educación durante el federalismo. La reforma escolar de 1870, Instituto Caro y Cuervo-Universidad Pedagógica de Tunja, Bogotá.

Ríos Zúñiga, Rosalina (2005), Formar ciudadanos. Sociedad civil y movilización popular en Zacatecas, 18211853, Universidad Nacional Autónoma de México, México.

Roldán Vera, Eugenia (2010a) "Enseñanza ceremonial: los exámenes públicos de las escuelas de primeras letras en la Ciudad de México en el primer tercio del siglo XIX", Bordón: Revista de Pedagogía, vol. 62, núm. 2, pp. 68-80.

(2010b) "Formación ciudadana en los orígenes del Estado mexicano: el espacio escolar y su dimensión ceremonial en las primeras décadas de vida independiente", Memoria electrónica del Tercer Foro de Investigación Educativa "Educación y Ciudadanías Emergentes", San Luis Potosí.

(2012) "La escuela mexicana decimonónica como iniciación ceremonial a la ciudadanía: normas, catecismos y exámenes públicos", en Ariadna Acevedo y Paula López (coords), Ciudadanos inesperados. Espacios de formación de la ciudadanía avery hoy, El Colegio de México-Centro de Investigación y de Estudios Avanzados, México, pp. 39-69. 
Rosanvallon, Pierre (1999), La consagración del ciudadano. Historia del sufragio universal, Instituto Mora, México.

(2003), Por una historia conceptual de lo politico, Fondo de Cultura Económica, México.

Rubiano Muñoz, Rafael (2002), "El intelectual y la política. Miguel Antonio Caro y la Regeneración en Colombia", Utopía siglo XXI, vol. 2, núm. 8, enero, pp. 421-452.

Salas Martínez, Luisinho (2009), "Educación, maestro y ciudadanía durante el liberalismo radical: el caso del Estado Soberano de Bolívar, 1870-1886", tesis de pregrado para optar al título de historiador, Universidad de Cartagena, Colombia.

Serrano, Sol (1990), "¿Quién quiere la educación? Estado y familia en Chile a mediados del siglo XIX", en Pilar Gonzalbo (coord.), Familia y educación en Iberoamérica, El Colegio de México, México, pp. 153-170.

(1998), "La escuela chilena y la definición de lo público", en François-Xavier Guerra y Annick Lempérière (coords.), Los espacios públicos en Iberoamérica. Ambigüedades y problemas. Siglo XVIIISiglo XIX, Fondo de Cultura Económica-Centro Francés de Estudios Mexicanos y Centroamericanos, México, pp. 340-362.

(2000), "La estrategia conservadora en la consolidación del orden liberal en Chile, 1860-1890" en Marcello Carmagnani (coord.), Constitucionalismo y orden liberal en América Latina, 1850-1920, Nova Americana, Torino, pp. 121-155.

(2003), "La ciudadanía examinada: el control estatal de la educación en Chile (1870 -1886)", en Antonio Annino y François-Xavier Guerra (coords.), Inventando la nación, Fondo de Cultura Económica, México, pp. 550-564.

Silva, Renán (1991), "La educación en Colombia 1880-1930", en Alvaro Tirado Mejía, Jorge Orlando Melo, Jesús Antonio Bejarano (dirs.), Nueva historia de Colombia, vol. 4, Planeta, Bogotá, pp. 61-63. Solano Sergio, Roicer Flórez y William Malkún (2008), "Ordenamiento territorial y conflictos jurisdiccionales en el Bolívar Grande, 1800-1886", Historia Caribe, vol. V, núm. 13, pp. 63-119.

Traffano, Daniela (2007), "Educación, civismo y catecismos políticos: Oaxaca, segunda mitad del siglo XIX", Revista Mexicana de Investigación Educativa, vol. 12, núm. 34, julio-septiembre, pp. 1043-1063. Verbel Chávez, Grey (2005), "Élites y redes de poder en torno al proyecto regenerador. Cartagena 18741892", tesis para optar al título de historiadora, Universidad de Cartagena, Colombia.

Viviel, Adriana (2002), "Educación, manuales de urbanidad y códigos de policía: la modernidad de la Regeneración", Noventaynueve. Revista de Investigación Cultural, núm. 3, pp. 50-75.

\section{Publicaciones electrónicas}

Constitución Política de Colombia, documento pdf disponible en: <http://biblio.juridicas.unam.mx/libros/5/2212/13.pdf> (fecha de consulta: 23/02/2016).

Meníndez, Rosalía (2012), "Los proyectos educativos del siglo xix: México y la construcción de la nación", educ@upn.mx.Revista Universitaria [versión electrónica],núm. 6, documento pdf disponible en: <http:// educa.upnvirtual.edu.mx/index.php/hemeroteca/27-revista-6/183-las-iniciativas-y-los-proyectos-educativos-del-siglo-xix-mexico-y-la-construccion-de-la-nacion (fecha de consulta: 24/10/2017). 
Luisinho Eder Salas Martínez es historiador, egresado de la Universidad de Cartagena (2009), Maestro en Historia por la Universidad Autónoma de Zacatecas "Francisco García Salinas" (2016) y actualmente estudiante de segundo semestre del Doctorado en Historia de la misma universidad. Sus líneas de Investigación son historia social de la educación, formación de la ciudadanía en Colombia y su Región Caribe durante el siglo XIX e historia política. Entre sus publicaciones se encuentran: "El ferrocarril Cartagena-Calamar: la desaparición de una empresa heroica, 1950-1951", Trenzando, núm. 2, Cartagena, 2009, pp. 11-20; "Formando al ciudadano. La educación durante el liberalismo radical: el caso del Estado Soberano de Bolívar, 1870-1886", El Taller de la Historia, núm. 3, Universidad de Cartagena, 2010, pp. 303-333.

Recibido: 5 de enero de 2017.

Aceptado: 18 de septiembre de 2017. 